\title{
Continuous ambulatory peritoneal dialysis in the elderly: a seven-year experience
}

\author{
Kuan-Yu Hung, Wei-An Hsu, Tun-Jun Tsai, Chung-Jen Yen, Chia-Hsiu Hou, \\ Tsan-Shin Yen
}

\begin{abstract}
Summary
This is a retrospective comparison of the status among the elderly ( $\geqslant 60$ years, 23 patients) and younger patients $(<60$ years, 31 cases) who initiated continuous ambulatory peritoneal dialysis (CAPD) between January 1986 and December 1992 at the National Taiwan University Hospital. The distribution of underlying renal diseases differed in the two groups with diabetes $(56 \%)$ as the most common disease in the elderly, in contrast to glomerulonephritis $(60 \%)$ in the younger patients. Haemodialysis intolerance and patient preference were the main reasons leading to the use of CAPD in both groups. Social rehabilitation status was poorer in the elderly group. The difference in cumulative risk of the first peritonitis episode and the technique failure rate were not statistically significant. The major causes of mortality were of vascular origin in both groups. In conclusion, similarities in the technique failure rate and the cumulative risk of peritonitis imply that CAPD is an acceptable alternative long-term dialysis therapy for geriatric patients.
\end{abstract}

Keywords: China, peritoneal dialysis, elderly

\section{Introduction}

Overall there has been a progressive increase in the average age of the general population. In the Republic of China, $9 \%$ of the population were 60 years old or older in 1993 and this percentage is projected to increase. It is clear that simultaneously an increasing number of elderly patients will require end-stage renal disease care as the decade proceeds. Data from the United States Renal Data system (USRDS) shows that by the end of this decade over $60 \%$ of the end-stage renal disease patients in the US will be over the age of $60 .{ }^{1}$ Currently available studies have recognised the many advantages of continuous ambulatory peritoneal dialysis (CAPD) in the elderly. ${ }^{1-8}$ However, a comparison of morbidity and mortality between elder and younger CAPD patients was lacking. The present study aimed to evaluate the status and the results of CAPD treatment in elderly patients, as compared with a younger age group, in the Republic of China.

\section{Patients and methods}

From January 1986 to December 1992, 54 patients who initiated CAPD management in the National Taiwan University Hospital and underwent at least one outpatient CAPD treatment were studied. Among them, 23 patients were aged 60 years or older at the beginning of CAPD (Group I, 42.6\%), while the remaining 31 patients were under the age of 60 years (Group II, 57.4\%). All patients were studied retrospectively until March 1994.

The social rehabilitation status of the patients was assessed by well-trained CAPD nursing staff, who classified them into five categories: full activity; ambulatory; needing less than $50 \%$ assistance with daily tasks; needing more than $50 \%$ assistance with daily tasks; and full dependency. Peritonitis was defined by the presence of any two of the following symptoms and signs: cloudy dialysis effluent with more than 100 neutrophils $/ \mathrm{mm}^{3}$, abdominal pain and/or tenderness, microorganisms isolated in the peritoneal fluid. ${ }^{9}$ An exit-site infection was defined as pericatheter erythema and/or discharge. A tunnel infection was defined as erythema, oedema and/or tenderness over the subcutaneous catheter pathway. Because these infections sometimes overlap, they were combined and termed 'catheter-related infection'. ${ }^{10}$ Ultrafiltration failure was defined as an inability to reach dry weight and/or to control blood pressure, with need for haemodialysis or ultrafiltration to remove excess fluid. ${ }^{11} \mathrm{~A}$ technique failure was considered when CAPD was terminated for any reasons other than renal transplantation. ${ }^{8}$

Data were processed and compared by Chisquare or Student's $t$-test. Mean data are presented \pm the standard deviation of the mean. The curves of the risk of the first peritonitis episode and technique failure rate were both constructed according to Kaplan-Meier estimates. The survival rate of the patients was assessed by the application of life-table analyses.

\section{Results}

From January 1986 to December 1992, 54 patients ( 20 men and 34 women) who initiated CAPD management and underwent at least one out-patient treatment were enrolled in this study. The observation period totalled 391 patient months in Group I and 1250 patient Accepted 7 September 1994 
months in Group II. The average duration of treatment was 17 (range 2-48) months in Group I and 40.3 (range 14-96) months in Group II. The mean age in Group I was $71.2 \pm 1.5$ years (range 60-84) and in Group II was $34.8 \pm 1.5$ years (range $20-59$ ). The distribution of underlying renal diseases in our patients is listed in table 1 , and revealed differences between these two groups. Diabetes and glomerulonephritis, the two most common diseases, accounted for $56 \%$ and $30 \%$ of the cases, respectively, in the elderly; in contrast to glomerulonephritis $\left(60^{\circ}\right)$ and lupus nephritis $(20 \%)$ in the younger age group $(\mathrm{p}<0.01)$. The main reasons for selecting CAPD are shown in figure 1. Haemodialysis intolerance $\left(69.5^{\circ}\right)$ was primary in Group I, whereas in Group II patient's preference $(71 \%)$ and poor vascular access $\left(16^{\circ}{ }_{0}\right)$ were the major reasons. Social rehabilitation status is summarised in figure 2; as expected, there was significantly poorer functional class in the geriatric patients. Half $(48 \%)$ of the elderly patients needed assistance in daily tasks, compared with only $6 \%$ of the younger.

There were 34 hospital admissions, averaging one per 11.5 patient months in the older patients, in contrast to 20 admissions and an average of one per 62.5 patient months in the younger patients $(p<0.001)$. The reasons for hospitalisation are listed in table 2 . In both groups, about half of the events came from peritonitis, and the difference was not statis-

Table 1 Primary renal disease in CAPD patients

\begin{tabular}{lcc}
\hline Primary disease & \multicolumn{2}{c}{ Number of patients $\left({ }^{\circ}{ }_{0}\right)$} \\
\cline { 2 - 3 } & $\geqslant 60$ years & $<60$ years \\
\hline Glomerulonephritis & $7(30.4)$ & $18(58.1)$ \\
Diabetes mellitus & $13(56.5)$ & $4(12.9)$ \\
Lupus nephritis & 0 & $6(19.4)$ \\
Polycystic kidney & $1(4.3)$ & 0 \\
Renovascular disease & 0 & $1(3.2)$ \\
Interstitial nephritis & 0 & $1(3.2)$ \\
Unclassified & $2(8.7)$ & $1(3.2)$ \\
Total & 23 & 31 \\
\hline
\end{tabular}

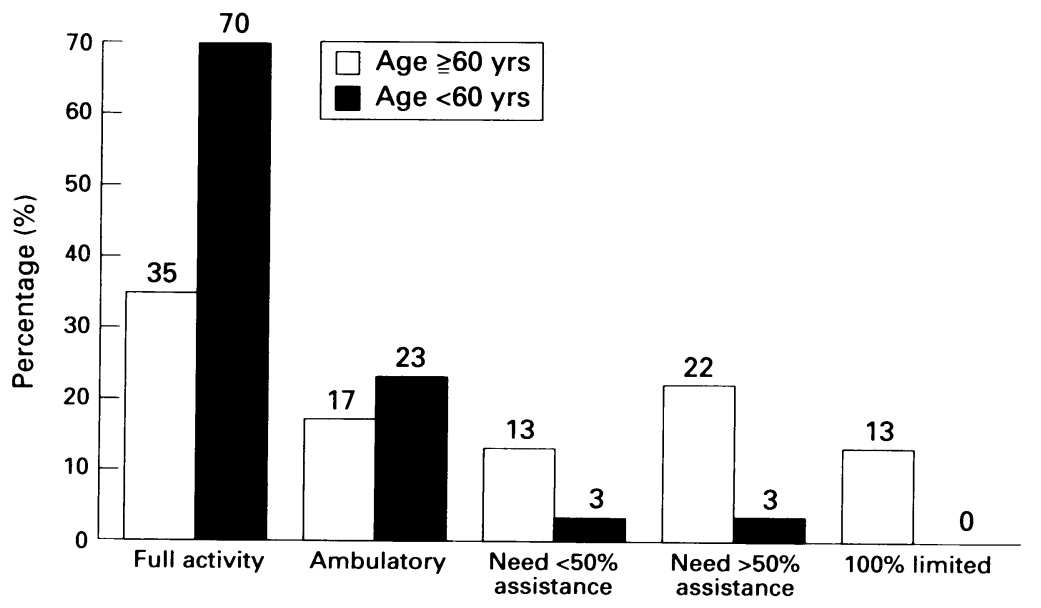

Figure 2 Social rehabilitation status of CAPD patients. More than half of the older patients need assistance in daily activity in contrast to only $7^{\circ}{ }_{0}$ in the younger $(\mathrm{p}<0.05)$

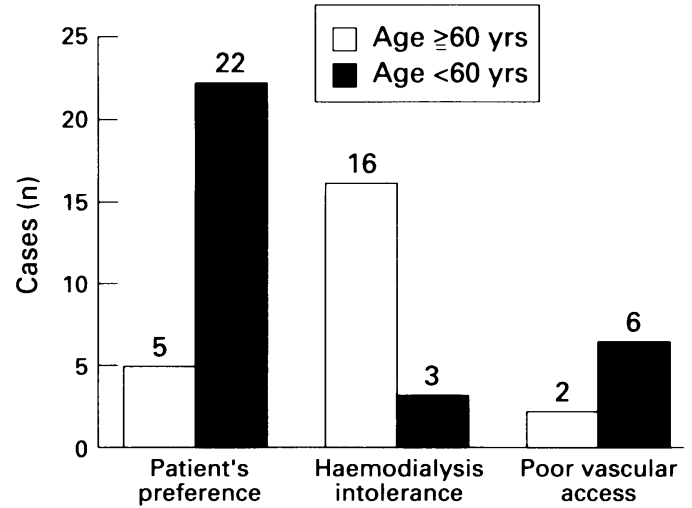

Figure 1 Reasons for CAPD choice in patients. Haemodialysis intolerance and patient preference were the leading factors for the older and younger patients, respectively $(\mathrm{p}<0.01)$

tically significant. As for peritonitis, the overall rate of peritonitis/patient-month was $1 / 15$ in the older and $1 / 44.6$ in the younger patients ( $\geqslant 60$ years, 26 episodes; $<60$ years, 28 episodes; $p<0.001)$. The curve of the cumulative risk of the first peritonitis episode is plotted in figure 3. However, there was no difference in risk of developing the first peritonitis episode between older and younger patients. By 40 months, $52^{\circ}$ of the older patients and $51 \%$ of the younger patients may have commenced one episode of CAPD peritonitis. The CAPD technique survival rates were also similar in both groups (figure 4 , $\mathrm{p}=0.3294$ ), with peritonitis and catheterrelated complications being the two major reasons for termination of CAPD. Overall survival rate was, not unexpectedly, significantly lower in older patients (figure 5, p $<0.001$ ). At the end of the second year, $90 \%$ of the younger patients on CAPD were still alive, while only $44^{\circ}{ }_{\text {(o) }}$ of the older patients were. Up to the fourth year, only $12 \%$ of the older patients had survived and remained on CAPD management. The causes of mortality were similar in both groups (table 3 ). The most common causes of death in the older group were vascular, either cardiovascular $(53 \%)$ or cerebrovascular $(7 \%)$, followed by infection-related diseases $\left(33^{\circ}{ }_{0}\right)$; while cardiovascular death was less frequent in the younger age group (three patients only), it remained the most frequent cause $\left(75^{\circ}{ }_{0}\right)$.

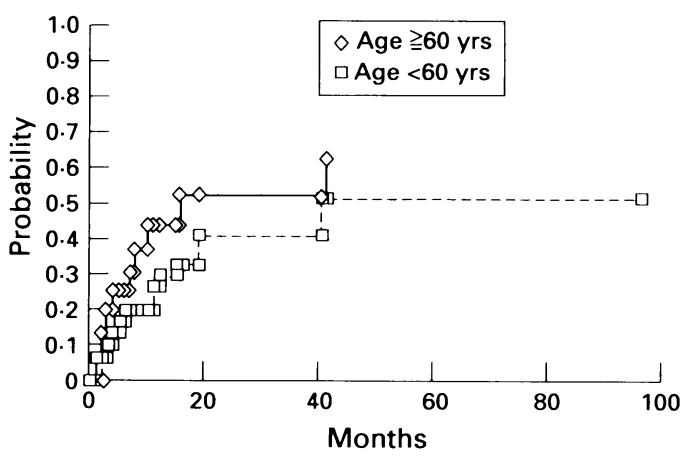

Figure 3 Cumulative risk of the first peritonitis episode in CAPD patients by Kaplan-Meier estimation. The log rank test showed $\mathrm{p}=0.1704$ 
Table 2 Reasons for hospitalisation

\begin{tabular}{lcc}
\hline & \multicolumn{2}{c}{ Number of patients $(\%)$} \\
\cline { 2 - 3 } & $\geqslant 60$ years & $<60$ years \\
\hline Peritonitis & $17(50)$ & $10(45.5)$ \\
Catheter-related infections & 0 & $3(13.6)$ \\
Catheter complications & $3(8.8)$ & $2(9.1)$ \\
Dialysis inadequacy & $3(8.8)$ & $1(4.5)$ \\
Others & $11(32.4)$ & $6(27.3)$ \\
Total & 34 & 22 \\
\hline
\end{tabular}

Table 3 Causes of death

\begin{tabular}{lll}
\hline & \multicolumn{2}{c}{ Number of patients } \\
\cline { 2 - 3 } & $\geqslant 60$ years & $<60$ years \\
\hline Cardiovascular & 5 & 2 \\
Pulmonary infection & 4 & 0 \\
Septicemia & 1 & 1 \\
GI diseases & 1 & 0 \\
Cerebrovascular & 1 & 0 \\
Congestive heart failure & 3 & 1 \\
Total & 15 & 4 \\
\hline
\end{tabular}

\section{Discussion}

The general population is aging progressively. The proportion of elderly patients requiring dialysis therapy is expected to increase in the future. In this retrospective study, $43 \%$ of the patients were assigned to the 'elderly' group. The distribution of underlying renal diseases was reported to be similar $r^{2,3}$ between younger and older CAPD patients, with diabetes and glomerulonephritis being the two major underlying diseases. What is of obvious difference in our patients is the relative prevalence of lupus nephritis in the younger patients. This may reflect a different disease pattern in the general population. The main for electing CAPD differ. In Benevent's series, ${ }^{4}$ patient's preference and cardiovascular diseases composed two-thirds of the reasons for CAPD in the elder group. From experience in Western Germany, similar to this study, patient's preference followed by poor vascular access were the main reasons leading to use of CAPD in the younger group in contrast to that of haemodialysis intolerance and patient's preference in the elderly $(\mathrm{p}<0.01)$.

The older patients demonstrated a higher risk of hospitalisation in this study, similar to results reported from Southern California ${ }^{2}$ and the UK, ${ }^{5}$ but somewhat less frequently in the present patients. The reasons for hospitalisation were similar between the two groups, with peritonitis accounting for about $50 \%$ of the cases in both groups. However, as a percentage, catheter-related complications were only $8.8 \%$ in the older group compared with $22.7 \%$ for younger patients $(p<0.05)$. This may be attributed to the relatively higher social rehabilitation and ambulatory daily activities in the younger group. As for peritonitis, it has been reported that there is no difference in the overall rate of peritonitis/patient-month between older and younger patients $(1 / 25$ in the older, and $1 / 27$ in the younger). ${ }^{11}$ In the present study the rate of peritonitis was significantly

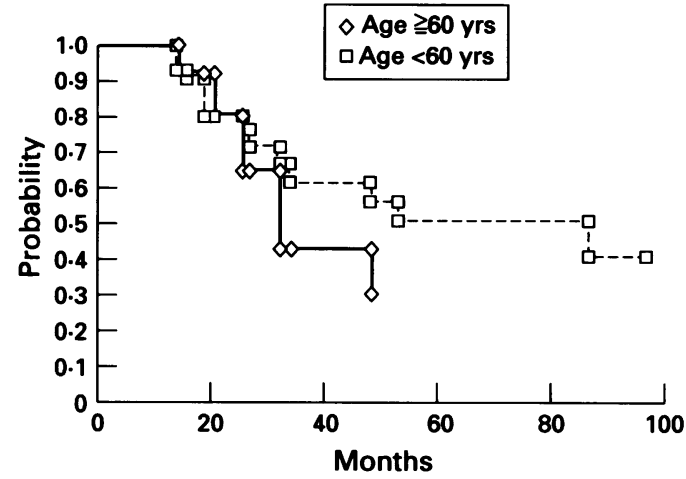

Figure 4 CAPD technique survival curves by Kaplan-Meier estimation with the log rank test $\mathrm{p}=0.3294$

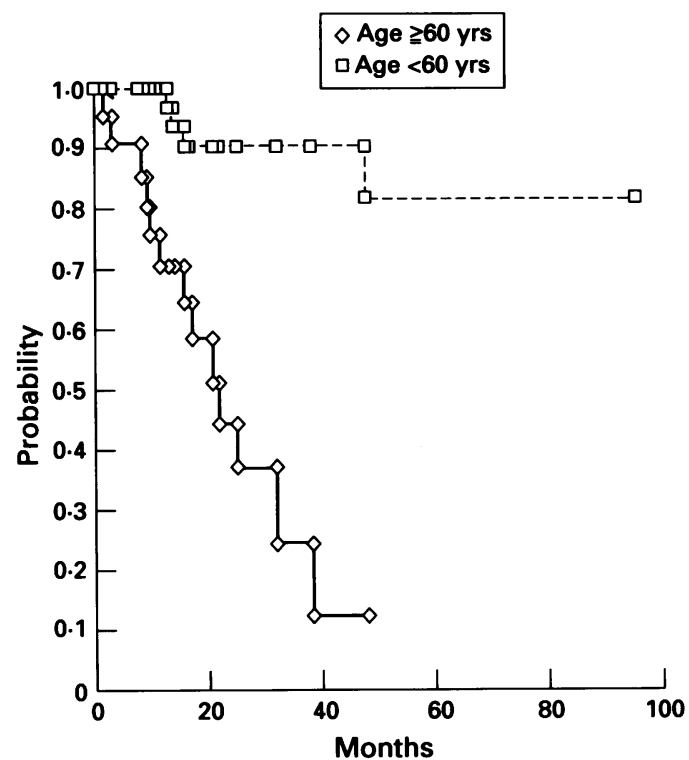

Figure 5 CAPD patients actual survival rate by life-table analysis. The overall survival rate was, as expected, lower in the older than in the younger patients $(\mathrm{p}<0.001)$

higher in the older group ( $1 / 15$ vs $1 / 44.6$ patient months), similar to findings in other series. ${ }^{5,6}$ However, there was no increased risk in the development of the first peritonitis episode in the older patients (figure 3 ). This would imply that underlying medical conditions may determine peritonitis frequency.

The reasons and rates for CAPD technique failure were similar in both groups, similar to the results of one clinical survey in the US.? Posen $e t a l^{\beta}$ reported a $50 \%$ technique failure rate by the end of the fifth year after initiating CAPD, and attributed it to the relative inability of aged patients to cope with such therapy. However, in this study there was no statistically significant difference in technique failure rates between older and younger patients (figure 4, $\mathrm{p}=0.33$ ). This may reflect the culturally instilled availability of assistance from families here. Actual patient survival rates, shown in figure 5 , differ significantly in the two groups, with an overall survival rate significantly lower in the aged $(p<0.001)$. Cardiovascular diseases are recognised worldwide as the most 
common cause of death in dialysis patients, ${ }^{12}$ and these are also frequent in CAPD patients (around 36-45\%). ${ }^{8,11}$

In conclusion, CAPD provides an acceptable means of long-term dialysis for geriatric patients. This study further suggests that the aging process does not increase the risk of peritonitis or CAPD technique failure in geriatric patients.

1 Nissenson AR. Dialysis therapy in the elderly patient Kidney Int 1993; 43 (suppl 40): S51-7.

2 Nissenson AR, Dominick E, Soderblom GR. CAPD in the elderly. Southern California/Southern Nevada experience. Adv Perit Dial 1990; 6 (suppl): 51-5.

3 Nebel M, Finke K. CAPD in patients over 60 years of age. Adv Perit Dial 1990; 6 (suppl): 56-60.

4 Benevent D, Benzakour M, Peyronnet P, Lagarde C Charmes JP, Leroux-Robert C. Comparison of continuous ambulatory peritoneal dialysis and hemodialysis in the elderly. Adv Perit Dial 1990; 6 (suppl): 68-71.

5 Gokal R. CAPD in the elderly - European and UK experience. Adv Perit Dial 1990; 6 (suppl): 38-40.

6 Nolph KD, Lindblad AS, Novak JW, Steinberg SM. Experiences with the elderly in the National CAPD registry. Adv Perit Dial 1990; 6 (suppl): 33-7.

7 Gentile DE. Peritoneal dialysis in geriatric patients: a survey Gentile DE. Peritoneal dialysis in geriatric patients: a survey
of clinical practices. Adv Perit Dial 1990; 6 (suppl): 29-32.

\section{CAPD in the elderly ( $\geqslant 60$ years)}

- well tolerated

- higher rates of peritonitis

- $44 \%$ two-year survival rate

The authors express their appreciation to the Ta-Tung Kidney Research Foundation for grant support.

8 Posen GA, Fenton SSA, Arbus GS, Churchill DN, Jeffery R. The Canadian experience with peritoneal dialysis in the elderly. Adv Perit Dial 1990; 6 (suppl): 47-50.

9 Keane WF, Golpern ET, Gokalm R, et al. Peritoneal dialysis-related peritonitis treatment recommendations: 1993 update. Perit Dial Int 1993; 13: 14-28.

10 Holley JL, Bernardine J, Perlmutter JA, Piraino B. A comparison of infection rates among older and younger patients on continuous peritoneal dialysis. Perit Dial Int 1994; 14: 66-9.

11 Nissenson AR, Diaz-Buxo JA, Adcock A, Nelms $M$ Peritonitis dialysis in the geriatric patient. Am F Kidney Dis 1990; 16: 335-8.

12 Ismail N, Hakim RM, Oreopoulos DG, Patrikarea A. Renal replacement therapies in the elderly: Hemodialysis and chronic peritoneal dialysis. Am $f$ Kidney Dis 1993; 22: chronic 